\title{
AS ESTRATÉGIAS DO "MOVIMENTO PELA BASE" NA CONSTRUÇÃO DA BNCC: CONSENSO E PRIVATIZAÇÃO
}

\author{
ESTRATEGIAS DEL “MOVIMENTO PELA BASE” EN LA CONSTRUCCIÓN \\ DE BNCC: CONSENSO Y PRIVATIZACIÓN
}

\section{THE STRATEGIES OF THE “MOVIMENTO PELA BASE” IN BUILDING THE BNCC: CONSENSUS AND PRIVATIZATION}

\author{
Fabíola da Silva FERREIRA ${ }^{1}$ \\ Fabiano Antonio dos SANTOS ${ }^{2}$
}

RESUMO: Este artigo apresenta as articulações do Movimento Pela Base na condução do processo de construção da Base Nacional Comum Curricular em todo o território brasileiro. Em um contexto político e econômico influenciado pelo discurso gerencial de redução do papel do Estado, o empresariado brasileiro torna-se figura central em boa parte das recomendações de políticas para o campo educacional, resultado de uma tendência internacional de crescimento do terceiro setor sobre as ações públicas. A análise das produções científicas sobre a BNCC, considerando livros, artigos, teses e dissertações, além de documentos disponibilizados nas mídias eletrônicas nos permitiu demonstrar a capilaridade do movimento, o envolvimento de sujeitos e instituições públicas e privadas e suas intencionalidades de educar para a nova sociabilidade capitalista, pautada na necessidade de formação de consensos em torno da ideia de um projeto social coletivo da política pública.

PALAVRAS-CHAVE: BNCC. Movimento pela base. Privatização. Terceira via. Consenso.

RESUMEN: Este artículo presenta las articulaciones del Movimento Pela Base en la realización del proceso de construcción del la Base Nacional Comum Curricular en todo el territorio brasileño. En un contexto político y económico influenciado por el discurso gerencial de reducir el papel del Estado, el sector empresarial brasileño se ha convertido en una figura central en la mayoría de las recomendaciones de politicas para el campo educativo, el resultado de una tendencia internacional de crecimiento en el tercer sector sobre las acciones públicas. El análisis de producciones científicas sobre BNCC, considerando libros, artículos, tesis y disertaciones, además de documentos disponibles en medios electrónicos, nos permitió demostrar la capilaridad del movimiento, la participación de sujetos y instituciones públicas y privadas y sus intenciones de educar para La nueva sociabilidad capitalista, basada en la necesidad de formar un consenso en torno a la idea de un proyecto social colectivo de política pública.

\footnotetext{
${ }^{1}$ Universidade Federal de Mato Grosso do Sul (UFMS), Corumbá - MS - Brasil. Professora da Rede Municipal de Corumbá. Mestre em Educação (UFMS). ORCID: https://orcid.org/0000-0003-0917-8748. E-mail: biola_nrt_silva@hotmail.com

${ }^{2}$ Universidade Federal de Mato Grosso do Sul (UFMS), Corumbá - MS - Brasil. Professor do Curso de Pedagogia e do Programa de Pós-Graduação em Educação. Doutorado em Educação (UFSC). ORCID: https://orcid.org/0000-0002-7703-8520.E-mail: fabiano.santos@ufms.br
} 
PALABRAS CLAVE: BNCC. Movimento pela base. Privatización. Tercera vía. Consensos.

ABSTRACT: This article presents the articulations of the Movimento Pela Base in conducting the process of building the Base Nacional Comum Curricular throughout the Brazilian territory. In a political and economic context influenced by the managerial discourse of reducing the role of the State, the Brazilian business sector has become a central figure in most of the policy recommendations for the educational field, as a result of an international growth trend in the third sector on actions public. The analysis of scientific productions about BNCC, considering books, articles, thesis and dissertations, in addition to documents made available on electronic media, allowed us to demonstrate the capillarity of the movement, the involvement of the subjects and public and private institutions, and their intentions to educate for the new capitalist sociability, based on the need to form consensus around the idea of a collective social project of public policy.

KEYWORDS: BNCC. Movimento pela base. Privatization. Third way. Consensus.

\section{Introdução}

O envolvimento do grupo empresarial na educação intensificou-se desde a Reforma do Estado brasileiro, nos anos 1990, e tem se construído como expressão do modelo de organização social dentro da era globalizada (LUZ, 2011). Segundo Neves (2005), o envolvimento do empresariado tem a função fundamental de educar para a nova forma de sociabilidade, a partir da criação de consensos em torno de objetivos tidos como "comuns" e que, portanto, deveriam envolver a todos, independentemente de classe social, todos se tornariam protagonistas na construção de um projeto social "coletivo".

A Base Nacional Comum Curricular (BNCC), assim como as diversas reformas desenvolvidas e direcionadas à Educação Básica, esboça-se trazendo em seu contexto o discurso de melhoria da qualidade da educação. Homologada pelo Ministério da Educação (MEC), em dezembro de 2017, a BNCC serve não apenas para definir o conteúdo dos currículos escolares, como também para orientar a produção de outras políticas “[...] referentes à formação de professores, à avaliação, à elaboração de conteúdos educacionais e aos critérios para a oferta de infraestrutura [...]" (BRASIL, 2017a, p. 8), entre outras, assumindo, portanto, papel fundamental na regulação e controle das demais políticas educacionais em escala nacional.

Compreendida por diversos autores como campo de disputas, o processo de construção da BNCC se desenvolveu em um contexto tumultuado, considerando tanto as mudanças dentro do próprio Ministério da Educação quanto o contexto mais geral de crise política e econômica nacional e internacional. A este cenário somaram-se as diversas críticas dirigidas 
ao documento que partiram, principalmente, das entidades educacionais, associações científicas, sindicatos, pesquisadores e professores que denunciavam a centralização do processo de construção do documento no Ministério da Educação e a forte influência do empresariado na definição do conteúdo da BNCC.

Nesta pesquisa, buscamos apresentar o modo como se realizaram as articulações e atuação do Movimento Pela Base (MPB) na condução do processo de construção da BNCC, considerando o contexto econômico e político que sustentou esse processo. Em que pese haver grande quantidade de estudos sobre a BNCC, desde análises curriculares, passando por relações com as avaliações externas, até mais especificamente sua interferência sobre os níveis de ensino (CAMPOS; DURLI; CAMPOS, 2019; COSTA; SILVA, 2019), ainda é preciso aprofundar as análises sobre a face privatista que esteve/está por trás da implementação deste documento que é, seguramente, um dos mais importantes deste novo século para a educação do país.

A pesquisa se desenvolveu a partir da análise das produções científicas sobre a BNCC, considerando livros, artigos, teses e dissertações além de documentos disponibilizados nas mídias eletrônicas. Utilizamos como referência o método do Materialismo HistóricoDialético, orientado pela perspectiva gramsciana, sendo crucial para o desenvolvimento da pesquisa o conceito de consenso ativo, que a nosso ver foi a principal estratégia utilizada pelos formuladores de política, com o objetivo de manter a hegemonia na condução e definição da reforma curricular.

O trabalho encontra-se estruturado em duas seções, além da introdução e considerações finais. Na primeira abordamos o contexto econômico e político de atuação do empresariado para que fosse garantida a construção da BNCC. Na segunda destacamos o modo como atuou o MPB - compreendido enquanto aparelho privado de Hegemonia durante o processo de elaboração da BNCC, analisando os objetivos da organização e estratégias utilizadas por seus intelectuais orgânicos para manter o controle sobre a direção do projeto da Base que, entre outros pontos, se materializa pela grande capacidade de articulação que o MPB possui ao envolver uma grande variedade de sujeitos, individuais e coletivos, das esferas pública e/ou privada, do contexto nacional e internacional.

\section{Contexto econômico e político para atuação do empresariado: a construção da BNCC}

A discussão sobre construção de uma Base Nacional não é recente, sendo objeto de discussões desde os anos 1980 (SAVIANI, 2016). Ganha ainda mais importância a partir dos 
anos 1990, com o crescimento de proposições de gestão gerencial nas instituições escolares e aplicação de avaliações externas, sempre justificadas para mensurar a qualidade da educação. Foi, ainda nos anos 1990, que o país atravessou a reforma do estado, provocando ampliação do discurso gerencial e da ideia de estado oneroso e pouco eficiente. A exemplo da Inglaterra, a reforma do Estado brasileiro contou com a força dos pressupostos da Terceira Via, especialmente a convocação de organizações da sociedade civil para participar da administração pública. A consequência foi o entendimento do Estado como um inimigo a ser combatido. O ativismo se proliferou especialmente em nome de uma cidadania mais representativa que propriamente coletiva ${ }^{3}$.

Na proposta de reforma do Estado brasileiro se estimulou a criação de uma espécie de Terceiro Setor denominado, também, de público não-estatal, pressupondo-se a parceria do Estado com o mercado para provimento dos serviços públicos à população. Esse conceito acaba por designar uma série de atividades da iniciativa privada em um sentido público nãogovernamental. Público, no contexto da reforma, faria referência à sociedade e estatal, ao Estado. Portanto, público não-estatal compreenderia atividades voltadas à sociedade mas não de responsabilidade exclusiva do Estado.

No domínio dos serviços sociais e científicos a propriedade deverá ser essencialmente pública não-estatal. As atividades sociais, principalmente as de saúde, educação fundamental e de garantia de renda mínima, e a realização da pesquisa científica envolvem externalidades positivas e dizem respeito a direitos humanos fundamentais [...] Logo, se não devem ser privados, nem estatais, a alternativa é adotar-se o regime da propriedade pública não-estatal, é utilizar organizações de direito privado mas com finalidades públicas, sem fins lucrativos. "Propriedade pública", no sentido de que se deve dedicar ao interesse público, que deve ser de todos e para todos, que não visa ao lucro; "não-estatal" porque não é parte do aparelho do Estado. As organizações públicas não-estatais podem ser em grande parte e em certos casos, inteiramente - financiadas pelo Estado (BRESSERPEREIRA, 2001, p. 246).

A reforma do estado foi terreno fértil para a investida do empresariado sobre setores estratégicos como a educação, uma vez que viam aí estratégia importante para o desenvolvimento de seu projeto hegemônico. Com este terreno já amplamente difundido, a discussão sobre a necessidade de uma Base Curricular ganha contornos bem distintos daqueles de origem dos anos 1980, quando o interesses dos trabalhadores em educação era garantir maior igualdade a partir do estabelecimento de conteúdos essenciais. Agora, o

${ }^{3}$ Para Buffa, Arroyo e Nosella (1995), a cidadania coletiva é construída a partir da participação popular nas principais decisões que regem a sociedade. É coletiva porque não diz respeito ao indivíduo exclusivamente, mas envolve a organização das classes sociais. 
discurso sob o domínio do empresariado passa a ser outro: desenvolver a educação para a produtividade, para o ensino de conhecimentos úteis ao mercado, ao modelo econômico. É neste contexto, portanto, que as primeiras discussões sobre a construção do que hoje conhecemos como BNCC foram realizadas.

Inspirado na proposição americana de um currículo comum, implementado em 2010, (Common Core State Standards Iniciative) $^{4}$, o Brasil inicia as discussões de criação da BNCC, justificando se tratar de uma medida já prevista em Lei $^{5}$ (LDB de 1996). O que fica patente, neste novo contexto, é a terceirização da função do estado, acusado de ser ineficiente com a gestão pública. A educação, setor estratégico para o desenvolvimento do capital, ganha atenção especial e diversas proposições passam a ser conduzidas pelo setor privado em nível mundial.

Trata-se de uma tendência internacional que tem se construído atrelada às políticas de Organismos Multilaterais e articulada a reformadores e empresários no campo nacional e internacional. Segundo Peroni e Caetano (2015, p. 344):

São mudanças baseadas nas reformas ocorridas nos Estados Unidos, Austrália, Chile e Reino Unido que construíram e implementaram, recentemente, padrões curriculares nacionais e que são questionados atualmente por um conjunto de pesquisadores da área sobre as melhorias e ou prejuízos à qualidade da educação .

Assim, o aparato legalista, estabelecido nacionalmente em torno da construção de uma Base Nacional Comum Curricular, contribui para legitimar a reforma curricular no país. Esta reforma vem se desenvolvendo tendo como principal orientador o Movimento Pela Base Nacional Comum (MPB). Segundo Freitas $\left(2015\right.$ c) ${ }^{6}$, o MPB foi criado, em abril de 2013, a partir do Seminário Internacional "Liderando Reformas Educacionais", que ocorreu em São Paulo, na Fundação Victor Civita - Grupo Abril -, evento organizado pela Universidade de

${ }^{4}$ Common Core (Núcleo Comum) trata-se do documento curricular comum, lançado em 2010, nos Estados Unidos, durante o governo de Barack Obama. Assim como a BNCC, o Common Core define as habilidades que devem ser desenvolvidas pelos alunos em cada série, contemplando, entretanto, como conteúdos obrigatórios apenas linguagens e matemática.

${ }^{5}$ No âmbito legal, uma série de documentos foram utilizados para justificar a criação da BNCC, entre eles a Constituição Federal de 1998, que enfatiza: “Art. 210. Serão fixados conteúdos mínimos para o ensino fundamental, de maneira a assegurar formação básica comum e respeito aos valores culturais e artísticos, nacionais e regionais" (BRASIL, 1998, grifo nosso); a LDB, que no Inciso IV de seu artigo $9^{\circ}$, afirma a responsabilidade da União em "estabelecer, em colaboração com os Estados, o Distrito Federal e os Municípios, competências e diretrizes para a Educação Infantil, o Ensino Fundamental e o Ensino Médio, que nortearão os currículos e seus conteúdos mínimos, de modo a assegurar formação básica comum" (BRASIL, 1996, grifo nosso); o PNE, na qual a Base Nacional Comum Curricular encontra-se relacionada às metas de universalização do ensino fundamental.

6 Disponível em: https://avaliacaoeducacional.com/2015/07/26/reformadores-e-base-nacional-personagens-i/. Acesso: 28 fev. 2019. 
Yale, dos Estado Unidos da América, e pela Fundação Lemann. Confirmando o fato, Peroni e Caetano (2015, p. 344) destacam que:

Esse movimento iniciou em abril de 2013, durante um seminário internacional que reuniu algumas instituições brasileiras do setor educacional organizado pelo Conselho Nacional de Secretários Estaduais de Educação (Consed) e Fundação Lemann. Participaram a União Nacional dos Dirigentes Municipais de Educação (Undime), o Conselho Nacional de Educação (CNE), o Conselho Estadual de Educação de São Paulo (CEE-SP), a Comissão de Educação da Câmara dos Deputados e o Movimento Todos pela Educação.

No mesmo período, em abril de 2013, há registros da ida de um grupo de deputados à cidade de New Haven, Estados Unidos, para participar, "em missão oficial”, de um Seminário durante os dias 21 a 24, com o mesmo nome do seminário realizado em São Paulo, cujo registro pode ser localizado na página da Câmara dos Deputados ${ }^{7}$. No relato, o deputado Alex Canziani $^{8}$ (PTB- PR), um dos participantes do seminário declara:

[...] nós estivemos, na semana passada, em uma missão oficial na cidade de New Haven, nos Estados Unidos, na Universidade de Yale, a convite da Fundação Lemann, para participar de um seminário chamado Liderando Reformas Educacionais e Fortalecendo o Brasil para o Século XXI.

A Fundação Lemann, [...] é voltada para a educação, desenvolve belo trabalho para que possamos melhorar a qualidade da educação brasileira.

[...] a convite dessa fundação [...] tivemos a oportunidade de ouvir especialistas. [...]

E, através desse seminário, nós pudemos acompanhar as experiências dos Estados Unidos com uma situação: o common core, cujo debate queremos trazer para o Brasil.

Segundo Andrade, Neves e Piccinini (2017), o período de implantação da reforma curricular ocorreu em um momento de instabilidade no Ministério da Educação, fruto da disputa política pela qual passava o país e que o governo petista abria exceções para negociar sua permanência no poder. No período de 2014 a 2016 passaram pelo MEC três ministros diferentes. A primeira versão ficou sob a tutela de Renato Janine Ribeiro/PT-PMDB (gestão entre abril a setembro de 2015), a segunda versão de Aloísio Mercadante/PT-PMDB (gestão entre outubro de 2015 a maio de 2016) e a terceira versão produzida sob responsabilidade de José Mendonça Filho/DEM-PMDB (entre os períodos de maio de 2016 a abril de 2018). 
O contexto de construção da BNCC revela instabilidade não apenas no âmbito do Ministério da Educação, mas no plano econômico, político e social. Esse movimento teve como uma das dimensões fundamentais a crise do Partido dos Trabalhadores (PT) que, entre outros fatores, é representada pela queda do governo Dilma Rousseff, com o golpe parlamentar, consolidado em 31 de agosto de 2016, e seu impeachment. Não é objeto deste texto realizar análise dos governos petistas, mas interessa-nos destacar que entre 2011 a 2016, quando Dilma Rousseff é afastada do governo federal, o papel do PT foi fundamental, pois instituiu aquilo que Oliveira et al. (2010) chamou de hegemonia às avessas. Para o autor, os governos petistas pavimentaram um percurso de apaziguamento de classes, gerando a cooptação das principais lideranças da classe trabalhadora em favor de seus objetivos. Coutinho (2010), analisando também este período utiliza-se da noção de contrareforma para apresentar como a classe burguesa brasileira vai produzir sua hegemonia (através do processo de revolução passiva). Como vamos acompanhar neste texto, o processo de participação do empresariado na construção da BNCC encontrou, neste período, um ambiente favorável para disseminar suas diretrizes e consolidar-se como o principal movimento em defesa da BNCC.

Buscando formar uma base sólida para a construção do currículo, o Ministério da Educação incorporou como parceiros oficiais no processo (todos com participação ativa no MPB): o Conselho Nacional de Secretários da Educação (CONSED) e a União Nacional de Dirigentes Municipais de Educação (UNDIME). A primeira versão preliminar do documento foi divulgada ao público pela Secretaria de Educação Básica do MEC (SEB/MEC), em setembro de 2015, sucedida pela realização da "Consulta Pública" online através de uma plataforma. A segunda versão foi disponibilizada em maio de 2016, sendo debatida por meio de Seminários Estaduais realizados em todas as Unidades da Federação, promovidos pelas Secretarias Estaduais e coordenados pelo CONSED e pela UNDIME. Entretanto, apenas a primeira versão da BNCC foi aberta para consulta pública por meio da plataforma online. A terceira versão preliminar da BNCC, encaminhada ao Conselho Nacional de Educação em abril de 2017, foi discutida em cinco Audiências Públicas, uma em cada região, realizadas no período de junho a setembro de 2017.

Compreendemos que o percurso definido para a elaboração da BNCC ao abrir para a participação da sociedade, logra efeito positivo no sentido de legitimação da política enquanto projeto "coletivo". Procura-se construir um contexto favorável para a construção das duas outras versões do documento, bem como para sua implementação, aproveitando a instabilidade política que o país enfrentava. De acordo com informações disponibilizadas no Portal da $\mathrm{BNCC}$, o resultado da consulta pública à primeira versão teria gerado "mais de 12 
milhões de contribuições" - discurso que passou a ser utilizado durante o processo de construção da BNCC como uma evidência do protagonismo, principalmente dos professores, na elaboração do documento.

Segundo Cássio (2017, s/p) o discurso disseminado pelo MEC e demais interessados na produção da BNCC - que inclui institutos e fundações empresariais - sobre estas "contribuições", na realidade, revela uma forma de "participacionismo", na qual a consulta pública serviu mais para legitimar os “discursos oficiais sobre 'participação' [...] do que de produtor de efetiva participação social na construção da política curricular". Cássio (2017, $\mathrm{s} / \mathrm{p})$ ainda declara:

A superexploração do vistoso número de 12 milhões de "contribuições", cujo significado pode ser questionado de muitas formas, inocula no debate público um falso consenso, como se a coleta de milhões de cliques de concordância e a mera publicização das opiniões de milhares de "indivíduos" - profissionais da educação ou não - fossem capazes de, automaticamente, forjar a democracia no processo de construção do currículo brasileiro.

Assim, a divulgação massiva do número total de "mais 12 milhões de contribuições", teve como propósito maior a formação de consensos entre educadores e comunidade, consolidando a implementação de políticas "de baixo para cima", ou seja, contando com as ideias de participação, autonomia e responsabilização, amplamente disseminadas a partir dos anos 2000 em todo o mundo (SANTOS, 2016).

Diante deste cenário, é possível perceber que a construção da BNCC foi repleta de contradições e disputas de interesses entre os diferentes sujeitos e classes sociais, e que o MPB teve participação decisiva para que a versão 3 do documento - a que atendia de modo satisfatório às demandas do empresariado - fosse finalizada e entregue à sociedade. Não foi por acaso que após a entrega da terceira versão ao CNE, em abril de 2017, o MPB já iniciou a preparação do terreno para a sua implementação no contexto da prática. Ao lançar o guia “primeiros passos para a implementação da Base Nacional Comum Curricular”, este destacou:

Para começar, no entanto, não é preciso esperar a homologação da BNCC. Com a terceira versão publicada, as redes podem começar o trabalho desde já em pelo menos duas frentes: comunicação e adaptação dos currículos e projetos pedagógicos (MOVIMENTO PELA BASE, 2017b, s/p).

A instabilidade política vivenciada neste período interferiu na definição da BNCC, abrindo espaços para a maior intervenção do empresariado nas definições e articulações. $\mathrm{Na}$ seção seguinte, verticalizamos nossas análises para demonstrar como o MPB vai conduzindo 
o processo de construção da $\mathrm{BNCC}$, como se articula entre instituições públicas, privadas, sujeitos para que o projeto de formação pautada em competências se concretize definitivamente.

\section{A atuação do MPB na construção da BNCC: parceria público-privada para formação de consensos}

Quando Gramsci (2010) vai analisar o papel dos intelectuais orgânicos, nos ajuda a compreender que estes sujeitos cumprem função que transcende um olhar estrito. Para ele, o caminho metodológico mais adequado é compreender sua função articulada ao conjunto de relações sociais nas quais tal atividade é desenvolvida. Não se trata, portanto, de um conjunto de pessoas iluminadas e alheias à realidade concreta, mas um grupo organizado em torno de objetivos definidos a priori, intimamente entrelaçados às relações sociais, a um projeto global de sociedade e a uma determinada funcionalidade do Estado.

Isto significa que um grupo embrionário, que se manifesta na ação e, portanto, descontínua e ocasionalmente - isto é, quando tal grupo se movimenta como um conjunto orgânico - toma emprestada a outro grupo social, por razões de submissão e subordinação intelectual, uma concepção que lhe é estranha; e aquele (o primeiro) grupo afirma por palavras esta concepção, e também acredita segui-la, já que a segue em 'épocas normais', ou seja, quando a conduta não é independente e autônoma, mas sim submissa e subordinada. É por isso, portanto, que não se pode destacar a filosofia da política; ao contrário, pode-se demonstrar que a escolha e a crítica de uma concepção do mundo são, também elas, fatos políticos. (GRAMSCI, 1981, p 15).

O autor italiano nos mostra, assim, que estes sujeitos cumprem importante função na produção de consensos e, portanto, na manutenção da hegemonia, ou na produção de uma contra-hegemonia. Ele destaca, principalmente, as artimanhas utilizadas pela classe dominante para que se mantenha, também, como classe diretiva. Essas estratégias se vinculam, como ele mesmo diz, à esfera teórica e política. Afirma, ainda, que embora seja possível considerar a todos como intelectuais, é a especificidade de sua função em determinado contexto que revelará sua organicidade junto às distintas classes sociais.

não existe organização sem intelectuais, isto é, sem organizadores e dirigentes, sem o aspecto teórico da ligação teoria-prática se distinga concretamente de um extrato de pessoas especializadas na elaboração conceitual e filosófica. Mas este processo de criação dos intelectuais é longo difícil, cheio de contradições, de avanços e de recuos, de cisões e de agrupamentos; e, neste processo, a 'fidelidade' da massa (e a fidelidade e a disciplina são inicialmente a forma que assume a adesão da massa e a sua 
colaboração no desenvolvimento do fenômeno cultural como um todo) é submetida a duras provas (GRAMSCI, 1981, p. 21-22).

Exatamente pela adversidade econômica em que se encontra a sociedade, o empresariado precisa produzir discursos que representem soluções aos problemas sociais. Sabem que a sociedade capitalista é contraditória, pretendem manter as desigualdades, já que eles são os principais privilegiados com isso. Para isso, utilizam um discurso sofisticado, passam a incentivar a criação e fortalecimento de projetos sociais (uma espécie de ação que produz alta adesão de boa parte da sociedade, por envolver a participação solidária das pessoas). Ainda que fique evidente que essa prática se aproxima de uma noção de filantropia empresarial (MARTINS, 2009), as empresas passam a impressão de estarem envolvidas em ações de responsabilidade social. Para Martins (2009, p. 164), estes empresários desenvolveram, ao longo destas últimas décadas

Projetos que: incentivaram o desenvolvimento do capital social das comunidades carentes; estimularam o crescimento do voluntariado; impulsionaram a implantação de "padrões de excelência de gestão" em organizações da sociedade civil, responsáveis por executar políticas sociais em diferentes áreas, procurando transformar a sociedade civil numa instância de relações harmoniosas, de colaboração entre indivíduos e de coesão cívica identificados com o programa neoliberal de Terceira Via.

Ao estudarmos o papel dos empresários no cenário educacional brasileiro, não podemos desconsiderar este contexto mais amplo de disputa hegemônica, e de relações sociais conflituosas e bastante adversas (luta de classes).

Exatamente por estarem imersos em uma conjuntura tão adversa, é que precisam produzir discursos que representem a solução unívoca dos problemas. Os empresários, na condição de intelectuais, exercem a função de "prepostos do grupo dominante" (GRAMSCI, 2010, p. 21) estabelecendo o consenso espontâneo de um contingente grande de pessoas, sempre orientados pelo grupo fundamental dominante. O sucesso de seu discurso se dá, principalmente, pela influência positiva que exercem no grupo social. Tal influência é adquirida pelo prestígio alcançado historicamente, gerando ampla confiança em suas recomendações.

Para Gramsci (2010), estes intelectuais possuem a função de consolidar o consenso, valendo-se de estratégias convincentes.

A repetição paciente e sistemática é um princípio metodológico fundamental: mas a repetição não mecânica, obsessiva, material, e sim a adaptação de cada conceito às diversas peculiaridades e tradições culturais, sua apresentação e representação em todos os seus aspectos positivos e em 
suas negações tradicionais, situando sempre cada aspecto parcial na totalidade (GRAMSCI, 2010, p. 206).

Com base na descrição gramsciana sobre o papel dos intelectuais orgânicos, é possível perceber que a atuação do empresariado brasileiro possui função estratégica: a produção de consenso. Estes empresários se inserem em diversos aparelhos privados de hegemonia, tais como a mídia, os Organismos Multilaterais e até sindicatos para executarem desde trabalhos técnicos e especializados em conhecimentos das mais diversas áreas, até funções voltadas à esfera jurídico-administrativa, com vistas à manutenção do grupo social hegemônico.

Num contexto de redefinição do papel do Estado e de sobreposição do privado em relação ao público, o empresariado tem se aproximado, cada vez mais do Estado, de modo a influenciar na definição das políticas sociais. Na discussão sobre a formulação de um currículo nacional, este se torna o grande alvo dos empresários, não apenas por oferecer condições de lucrar através da venda de materiais educativos, cursos e consultorias, como, também, a partir do currículo, orientar em escala nacional os princípios e conteúdos a serem ensinados em todas as instituições escolares do Brasil. Ou seja, cria-se a possibilidade dos empresários apontarem as competências desejáveis que os futuros trabalhadores devem desenvolver durante o período escolar. $\mathrm{O}$ que nos interessa neste artigo, entretanto, é a articulação entre o empresariado e o Estado, numa clara manifestação de privatização da educação.

De acordo com Peroni e Caetano (2015), o processo de privatização do público se realiza de várias formas, tanto pela direção como pela execução, implementação e disseminação das políticas educacionais. Segundo as autoras, neste processo de implementação e disseminação, o privado tem se destacado no protagonismo e direcionamento dos objetivos e finalidades escolares. "O privado, pela grande influência que tem no atual processo de correlação de forças, pode influenciar muito na definição do currículo nacional, o que trará consequências ainda maiores para a democratização no País, com o aumento do processo de mercadificação já em curso" (PERONI; CAETANO, 2015, p. $338)$.

O processo privatista ocorre, menos explícito, através das chamadas "parcerias" que se realizam entre o público e o privado. Neste caso, particularmente para os propósitos deste artigo, se destaca a participação do Movimento [empresarial] Pela Base. 
Conforme presente na página da organização ${ }^{9}$, o MPB é um grupo não governamental formado por sujeitos e organizações que atuam na área educacional, composto por " [...] organizações da sociedade civil, acadêmicos, pesquisadores, professores de sala de aula, gestores municipais, estaduais e federais, especialistas em currículos, avaliações e políticas públicas" (MOVIMENTO PELA BASE, 2017a, s/p). Sujeitos individuais e coletivos que se reuniram e atuam desde 2013 com o propósito de "facilitar" o processo de construção e implementação da Base Nacional Comum Curricular.

Segundo Andrade, Neves e Piccinini (2017), os articuladores do MPB são as organizações que compõem o chamado "terceiro setor", além das organizações privadas, que agem representando os interesses de banqueiros e empresários, no qual, um dos principais atores influentes no meio educacional é a Fundação Lemann, que atua, desde 2002 produzindo políticas, estudos e materiais para supostamente "auxiliar" na melhoria da qualidade da educação. É importante destacar que o MPB tem grande capilaridade, mantendo relações de parceria com fundações "familiares" empresariais, e/ou supra empresariais, dentre as quais se destacam: "Itaú, Natura, Ab Inbev, Grupo Globo, Odebrecht, Braskem, Credicard, Procter \& Gamble, Shell, Consórcio LIDE, Suzano Celulose, Samsung, Playstation, Avon, Dudalina, Englishtown, Citibank, Nestlé, Odontoprev, Oracle, Droga Raia, Boeing, Souza Cruz, [...]" (ANDRADE; NEVES; PICCININI, 2017, p. 8). Via de regra, estas instituições mostram-se "preocupadas" com a aprendizagem dos alunos, e se colocam como bastiões da qualidade da educação, sempre apresentando receituário para que uma educação de qualidade possa ser estabelecida no país.

Como sua principal preocupação explicitada seria com a qualidade da educação e a aprendizagem dos alunos, o Movimento Pela Base procura construir seu discurso em torno do conteúdo da BNCC. Para seus idealizadores, este documento não funcionaria como um currículo mínimo de conteúdos, mas um guia geral sobre princípios. Baseando-se nestes princípios, apontam o trabalho com competências e habilidades como a alternativa para esse suposto não direcionamento do currículo das escolas. Segundo Adrião e Peroni (2009), a busca por construir uma Base orientada para o desenvolvimento de competências, confere à educação o papel de desenvolver capital humano, objetivos alheios à sua natureza, e que está estritamente vinculado ao mercado capitalista. Neste sentido, a privatização não se dá somente pela definição clássica de venda do público, mas de sua apropriação para uso do privado, ou melhor, para uso dos princípios que orientam a lógica privada. Estas organizações

9 Quem somos. Disponível em: http://movimentopelabase.org.br/quem-somos/. Acesso em: 28 fev. 2019. 
empresariais definem os conteúdos escolares que os sistemas devem disseminar, além de executarem “[...] proposta[s] por meio da formação, da avaliação do monitoramento, premiação e sanções que permitem um controle de que seu produto será executado" (PERONI; CAETANO, 2015, p. 339).

Segundo Peroni e Caetano (2015), o processo de "mercadificação" conta com a participação ativa de sujeitos que, por sua vez, constituem complexas redes de sujeitos e instituições, como é o caso do MPB. Nesta compreensão, reificar o Movimento, como se tivesse vida própria, ou reduzi-lo à expressão de um único sujeito, grupo político ou empresarial não revela toda sua complexidade e penetração no campo educacional brasileiro. Essa compreensão oferecida pelas autoras, nos possibilita analisar o MPB em sua essência, como um importante aparelho privado de hegemonia em serviço da ampliação do capital e organizado em uma ampla e complexa rede. Segundo as autoras, as redes se constroem através da ação de sujeitos individuais e coletivos articulados nacional e internacionalmente, por meio de interesses comuns, cujo propósito maior é interferir no processo de elaboração de políticas educacionais, movimento que contribui para o processo de "mercadificação da educação". Sobre este ponto, as autoras declaram que:

[...] a mercadificação da educação pública não é uma abstração, mas ocorre via sujeitos e processos. Trata-se de sujeitos individuais e coletivos que estão cada vez mais organizados, em redes do local ao global, com diferentes graus de influência e que falam de diferentes lugares: setor financeiro, organismos internacionais e setor governamental (PERONI; CAETANO, 2015, p. 338-339).

A compreensão do Movimento Pela Base como rede envolvendo sujeitos individuais e coletivos demandou um importante esforço para revelar os aspectos econômicos e políticos, bem como as formas de organização internas que permitiram transformar a BNCC em um documento regulador e formativo para a sociabilidade do capital.

Shiroma (2020) nos oferece uma análise fundamental sobre o papel das redes de políticas na difusão de ideias e princípios que passam a ser considerados verdades muito sólidas, quando atingem o contexto da prática. Numa compreensão de que as políticas mais contemporâneas não seguem um modelo monolítico "de cima para baixo", a autora analisa como estas redes se materializam exatamente por sua grande capacidade de estabelecer interconexões. Seguindo essa lógica, o papel do Movimento Pela Base é interligar ao imaginário social princípios empresariais e gerenciais da educação de forma menos visível possível. A autora ainda afirma que uma política implementada a força não tem a preocupação, por parte de seus elaboradores, de convencer, construir consensos. O consenso 
é, portanto, a forma mais clara do modus operandi adotado pelo Movimento Pela Base, como já apresentamos ao usarem as consultas públicas da primeira versão em seu favor, dando a entender que se tratava de um processo democrático e participativo.

Com isso, o Movimento Pela Base busca cristalizar, no imaginário social, que sua vontade é a vontade coletiva. O efeito disso é o contágio dos "formuladores de políticas", e dos seus receptores, com a ideia de que a defesa por um documento basilar seria de interesse nacional e, até mesmo, internacional.

Seguindo a análise do MPB, agora já caracterizado como aparelho privado de hegemonia, vamos verticalizar ainda mais a análise e identificar alguns dos sujeitos envolvidos na implementação da BNCC, jogando luzes sobre toda a articulação envolvendo o MPB e diversas instituições públicas e privadas. Em sua página web, o movimento apresenta sua missão, confirmando o pressuposto de que sua suposta eficiência auxiliaria o Estado na execução de sua tarefa com a educação.

A BNCC determina os direitos de aprendizagem e desenvolvimento para todas as crianças e jovens brasileiros. Nós trabalhamos para garantir que esses direitos sejam cumpridos, apoiando a implementação de qualidade da BNCC e do Novo Ensino Médio em todas as redes e escolas públicas do país. Acompanhamos e damos visibilidade para o andamento da implementação em diversas frentes. Articulamos para o alinhamento de políticas e programas - curriculares, de formação docente, materiais didáticos e avaliações - à BNCC, sempre buscando a coerência do sistema educacional. Levantamos, em parceria com organizações nacionais e internacionais, evidências e as melhores práticas para garantir a qualidade e a legitimidade dos processos. Junto com as secretarias de educação, construímos e disseminamos consensos e orientações técnicas para a construção dos currículos e a formação dos professores. E levamos para toda a sociedade o debate sobre uma aprendizagem mais significativa e conectada com a vida dos estudantes. (MOVIMENTO PELA BASE, 2020, grifo nosso).

Em sua missão, fica explicitada a centralidade que teria o movimento na garantia de uma educação de qualidade e que o Estado teria maior eficiência sempre que sofrera interferências na garantia de direitos, no acompanhamento e implementação de ações para a educação, no alinhamento e articulação de políticas e processos, na elaboração de parcerias e no trabalho conjunto com secretarias de educação. Usando estas estratégias, o Movimento pela Base foi fundamental na elaboração da BNCC, promovendo intercâmbio de informações e convocando atores políticos a contribuírem ao que chamam de "uma educação mais significativa e conectada com os estudantes".

Procurando identificar os atores públicos e privados envolvidos na produção do texto da BNCC, Andrade, Neves e Piccinini (2017) localizam dois eixos centrais, representados 
pela esfera pública e privada: de um lado estaria o Ministério da Educação - e junto a ele as instituições: Conselho Nacional de Educação (CNE); Fórum Nacional de Educação (FNE); Conselho Nacional de Secretários de Educação (CONSED); e a União Nacional dos Dirigentes Municipais de Educação (UNDIME) - e, do outro, o Movimento Pela Base Nacional Comum Curricular, juntamente com seus membros e parceiros institucionais, que incluem, sobretudo, outras organizações e fundações da sociedade civil organizada, tendo a Fundação Lemann como uma das fundadoras do Movimento e também como sua secretariaexecutiva (figura 01 ).

Figura 1 - Articulações do Movimento Todos Pela Base

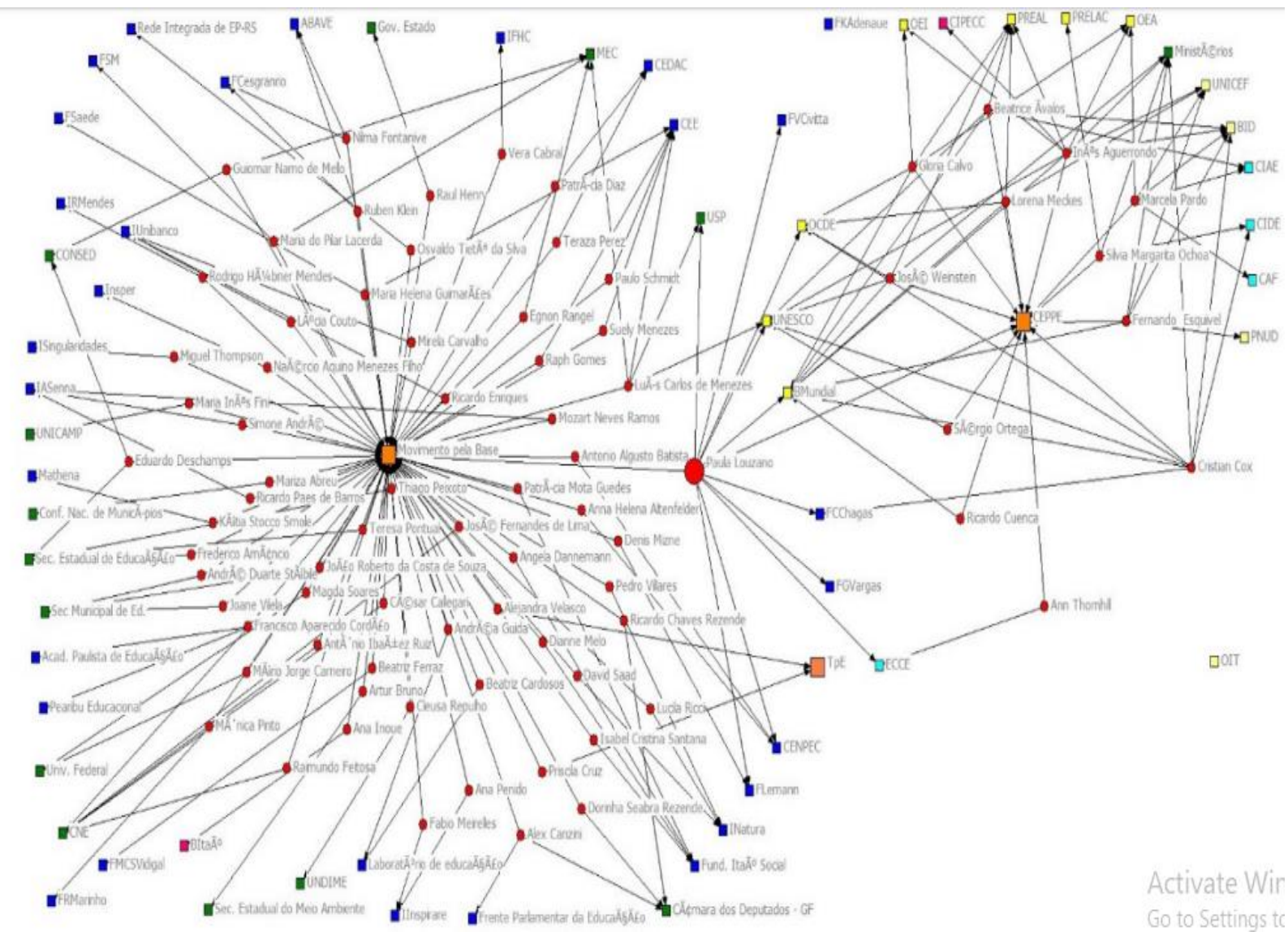

Fonte: Shiroma (2020)

Estes dois polos se articulam através de seus sujeitos individuais e coletivos, como podemos observar na imagem acima, que ocupam cargos nas instituições vinculadas ao Ministério da Educação e também têm funções de grande representatividade no Movimento Pela Base; revelando modos diferenciados do empresariado interferir no direcionamento das políticas educacionais. Um exemplo dessa articulação encontra-se na atuação do CONSED em sua composição reúnem respectivamente os secretários estaduais e municipais de educação - que representam, ao mesmo tempo, os interesses do Ministério da Educação na 
coordenação do processo de construção e implementação da BNCC e os interesses do MPB. Entretanto, a articulação e vinculação não ocorre apenas por meio de organizações e instituições, mas, também, através de sujeitos individuais.

Exemplo desta última articulação pode ser observado através de Raimundo Feitosa, que já ocupou diversos cargos políticos importante na área da educação pública, como assessorias especiais para a prefeitura de São Luís, e a secretaria municipal de educação deste mesmo município, onde exerceu/exerce três mandatos (2002-2008; 2009-2010; 2016-2020). Também atuou no Conselho Nacional de Educação, presidindo a Comissão do Plano Nacional de Educação. Sua grande participação no cenário político não se dá apenas na esfera pública, pois tem atuado na consultoria para assuntos educacionais da Fundação Itaú Social e um dos entusiastas e defensores do Movimento Pela Base, contribuindo com a produção de materiais de divulgação de princípios e orientações da gestão pública.

A análise de redes de políticas nos permite, como demonstrado, compreender a atuação do Movimento Pela Base para além da garantia dos "marcos legais que embasam a BNCC” (BRASIL, 2017a, p. 10), revelando a articulação de sujeitos e organizações, em âmbito nacional e internacional, que com o propósito de reformar a educação a partir de seus objetivos, estabelece como alvo mais emergente a reforma curricular, que se desenvolve atrelada às políticas de avaliação externa e formação docente, como explicita Peroni e Caetano (2015).

\section{Considerações finais}

No contexto econômico capitalista contemporâneo, temas como a produção de uma Base Curricular Nacional vão além das fronteiras nacionais, constituem-se em um movimento internacional articulado para ampliação da hegemonia capitalista, via domínio do setor educacional. $\mathrm{O}$ interesse pela educação não se restringe, portanto, ao conteúdo ensinado ou aprendido, diz respeito a produtividade de um sistema que visa maximização do lucro. Neste artigo, apresentamos como se articulou o Movimento Pela Base para atuar na condução e direcionamento da construção da BNCC.

Atuando como verdadeiros intelectuais orgânicos, o empresariado buscou manter o controle do processo desde os primeiros momentos, ainda quando eram realizadas as primeiras reuniões para estruturar as discussões que resultariam nas versões da BNCC. A última versão demonstrou explicitamente que o interesse do empresariado era garantir uma 
formação instrumental, já que as competências e habilidades são introduzidas e se tornaram centrais no documento que acabou se tornando o oficial.

O resultado destas investidas do empresariado é a substituição do Estado na liderança da elaboração e implementação da política pública pelo movimento empresarial, que se esconde sob o discurso da participação ativa e consciente na educação, o que representaria impactos positivos no futuro da população. Tornam-se, portanto, os arautos de medidas consideradas exemplares para superar as dificuldades educacionais que o Estado não foi capaz de fazer.

O Movimento Pela Base constituiu-se em um dos mais importantes e representativos movimento do empresariado brasileiro da atualidade. Devido sua capilaridade, a atuação envolveu desde instituições públicas, como privadas e contou com a participação ativa de sujeitos de grande importância para o desenvolvimento da economia. O que demonstramos neste artigo foi a atuação arquitetada do movimento para garantir seus interesses na efetivação da BNCC, processo que se desenvolveu em um contexto econômico e político conturbado, mas que no entanto, em lugar de ser um obstáculo para a concretização da reforma curricular revelou-se na verdade um terreno fértil. Desse modo, foi possível ao MPB estabelecer-se como o principal condutor da BNCC, transformando o documento em um importante instrumento no processo de regulação e controle das demais políticas educacionais, assim como, de formação para a sociabilidade do capital.

Logo, como consequência da Reforma dos anos 1990, ocorre não apenas a maior abertura para o empresariado interferir na definição e execução das políticas sociais, como também se consolidam novas formas de realização das políticas, marcadas pela maior participação, descentralização e "democratização" no processo de produção e implementação das políticas, movimento que em sua essência revela a responsabilização da sociedade; e, ao focar na educação, mostra principalmente a responsabilização dos professores pelos problemas educacionais. Este movimento se materializa, sobretudo, através da produção de consenso ativo, ou seja, pela inclusão intencional dos sujeitos de modo a facilitar a incorporação do projeto hegemônico pelos grupos subalternos.

Estas características estiveram presentes no processo de construção da $\mathrm{BNCC}$ - na qual identificamos tanto o incentivo à participação dos professores, gestores e demais sujeitos envolvidos diretamente com a execução da reforma curricular, camuflando o direcionamento do conteúdo da BNCC pelas organizações da sociedade civil, com destaque para a atuação do Movimento Pela Base e da Fundação Lemann - que também tem interferido no 
direcionamento do processo de sua implementação pelos Estados, Distrito Federal e Municípios.

AGRADECIMENTOS: À Coordenação de Aperfeiçoamento de Pessoal de Nível Superior (CAPES) pela concessão de bolsa de estudos tornando assim possível a pesquisa.

\section{REFERÊNCIAS}

ADRIÃO, Thereza, PERONI, Vera Maria Vidal. A educação pública e sua relação com o setor privado: implicações para a democracia educacional. Retratos da Educação, v. 03, n. 04, 2009.

ANDRADE, Maria Carolina Pires de; NEVES, Rosa Maria Corrêa das.; PICCININI, Cláudia Lino. Base nacional comum curricular: disputas ideológicas na educação nacional. Colemarx, 2017. Disponível em: http://www.niepmarx.blog.br/MM2017/anais2017/MC37/mc373.pdf. Acesso em: 15 jun. 2018.

BRASIL. Ministério da Educação. Base Nacional Comum Curricular. Terceira versão homologada. Brasília: MEC, 2017a. Disponível em: http://basenacionalcomum.mec.gov.br/abase/. Acesso em: 15 abr. 2018.

BRASIL. Constituição da República Federativa do Brasil (1988). Brasília, DF: Senado Federal, 1988. Disponível em:

http://www.planalto.gov.br/ccivil_03/constituicao/constituicaocompilado.htm. Acesso em: 11 mar. 2019.

BRASIL. Lei de Diretrizes e Base da Educação Nacional 9.394/96. Disponível em: http://www.planalto.gov.br/ccivil_03/LEIS/19394.htm. Acesso em: 05 ago. 2020.

BRESSER-PEREIRA, Luis Carlos. Do Estado patrimonial ao gerencial. In: PINHEIRO, Paulo Sérgio; SACHS, Ignacy; WILHEIM, Jorge (Orgs.). Brasil: um século de transformações. São Paulo: Cia. Das Letras, 2001.

BUFFA, Ester; ARROYO, Miguel; NOSELLA, Paolo. Educação e cidadania: quem educa o cidadão? Volume 19. 5. ed. São Paulo: Cortez, Coleção Questões da Nossa Época, 1995.

CAMPOS, Roselane de Fátima; DURLI, Zenilde; CAMPOS, Rosânia. BNCC e Privatização da Educação Infantil: impactos na formação de professores. Revista Retratos da Escola, v. 13, n. 25, 2019.

CÁSSIO, Fernando. Participação e participacionismo na construção da Base Nacional Comum Curricular. NEXO, São Paulo, 2 dez. 2017. Disponível em: https://www.nexojornal.com.br/ensaio/2017/Participa\%C3\%A7\%C3\%A3o-eparticipacionismo-na-constru\%C3\%A7\%C3\%A3o-da-Base-Nacional-Comum-Curricular. Acesso em: 13 ago. 2019. 
COSTA, Marilda de Oliveira; SILVA, Leonardo Almeida da. Educação e democracia: Base Nacional Comum Curricular e novo ensino médio sob a ótica de entidades acadêmicas da área educacional. Rev. Bras. Educ., Rio de Janeiro, v. 24, e240047, 2019.

COUTINHO, Carlos Nelson. A hegemonia da pequena política. In: OLIVEIRA, Francisco de; BRAGA, Ruy; RIZEK, Cibele Saliba (Org.). Hegemonia às avessas: economia, política e cultura na era da servidão financeira. São Paulo: Boitempo, 2010

FREITAS, Luiz Carlos de. Reformadores e base nacional: personagens - I. Blog do Freitas, 2015c. Disponível em: https://avaliacaoeducacional.com/2015/07/26/reformadores-e-basenacional-personagens-i/. Acesso em: 28 fev. 2019.

GRAMSCI, Antonio. Cadernos do cárcere: os intelectuais. O princípio educativo. Jornalismo. 5. ed. Trad. Carlos Nelson Coutinho. Volume 2. Rio de Janeiro: Civilização Brasileira, 2010.

GRAMSCI, Antonio. Concepção dialética da história. 4. ed. Rio de Janeiro: Civilização Brasileira, 1981.

LUZ, Liliene Xavier. Empresas privadas e educação pública no Brasil e na Argentina. Educ. Soc., Campinas, v. 32, n. 115, p. 437-452, abr./jun. 2011.

MARTINS, André Silva. A direita para o social: a educação da sociabilidade no Brasil contemporâneo. Minas Gerais: UFJF, 2009.

MOVIMENTO PELA BASE. Quem Somos. 2017a. Disponível em:

http://movimentopelabase.org.br/quem-somos/. Acesso em: 24 mar. 2019.

MOVIMENTO PELA BASE. Primeiros Passos Para a Implementação da Base Nacional Comum Curricular. 2017b. Disponível em: http://movimentopelabase.org.br/wpcontent/uploads/2017/04/BaseGuia.pdf. Acesso em: 04 jul. 2020.

MOVIMENTO PELA BASE. Nossa Missão. 2020. Disponível em http://movimentopelabase.org.br/quemsomos/\#: :text=A\%20BNCC\%20determina\%20os\%20direitos,e $\% 20$ escolas $\% 20 \mathrm{p} \% \mathrm{C3} \% \mathrm{BAb}$ licas\%20do\%20pa\%C3\%ADs. Acesso em: 02 ago. 2020.

NEVES, Lúcia Maria Wanderley (Org.). A nova pedagogia da hegemonia: estratégias do capital para educar o consenso. São Paulo: Xamã, 2005.

OLIVEIRA, Francisco de. Hegemonia às avessas. In: OLIVEIRA, Francisco de.; BRAGA, Ruy; RIZEK, Cibele. (Orgs). Hegemonia às avessas: economia, política e cultura na era da servidão financeira. São Paulo: Boitempo, 2010.

PERONI, Vera Maria Vidal; CAETANO, Maria Raquel. O público e o privado na educação Projetos em disputa. Revista Retratos da Escola, Brasília, v. 9, n. 17, p. 337-352, jul./dez. 2015. 
SANTOS, Fabiano Antonio dos. Do global ao local: a implantação das políticas de responsabilização docente, gestão gerencial e avaliação por resultados. Acta Scientiarum.

Education, v. 38, n. 3, p. 293-302, 2016.

SAVIANI, Dermeval. Educação Escolar, Currículo e Sociedade: o problema da Base

Nacional Comum Curricular. movimento-revista de educação, Submissões, v. 1, n. 4, 2016.

SHIROMA, Eneida Oto. Redes, experts e a internacionalização de políticas educacionais.

Revista de estudios teóricos y epistemológicos en políticas educativas, Ponta Grossa, v. 5, 2020.

\section{Como referenciar este artigo}

FERREIRA, Fabíola da Silva; SANTOS, Fabiano Antonio dos. As estratégias do "movimento pela base" na construção da BNCC: consenso e privatização. Doxa: Rev. Bras. Psico. e Educ., Araraquara, v. 22, n. 1, p. 189-208, jan./jun., 2020. e-ISSN: 2594-8385. DOI: https://doi.org/10.30715/doxa.v22i1.14031

Submetido em: 30/02/2020

Aprovado em: $30 / 05 / 2020$

Publicado em: 01/06/2020 